\title{
Comparison of usability between two videolaryngoscopes: a manikin study
}

Guidi A. ${ }^{1}$, Di Filippo A. ${ }^{1}$, Marino D. ${ }^{1}$, Bressan F. ${ }^{2}$, Corso R.M. ${ }^{3}$, Micaglio M. ${ }^{1}$

${ }^{1}$ Careggi Hospital, Dept of Anaesthesiology \& Intensive Care, Florence, Italy, ${ }^{2}$ Anesthesia Unit. Santo Stefano Hospital, Dept of Anaesthesiology \& Intensive Care, Prato, Italy, ${ }^{3}$ Morgagni Hospital, Dept of Anaesthesiology \& Intensive Care, Forlì, Italy

\section{Background and Goal of the Study:}

Videolaryngoscopy is emerging as a new standard in difficult airway management ${ }^{1}$. The impact of the human factor/usability in the performance of the various videolaryngoscopes (VLS) is not known. We compare the usability of two VLS by studying the performance of 20 residents in anaesthesia with no previous experience of videolaryngoscopic intubation using an easy intubation scenario in a manikin ${ }^{2}$.

\section{Materials and methods:}

Written informed consent was obtained from first year residents in Anaesthesia of Florence University, without experience about VLS. All participants were familiar with the direct laryngoscopy. The participants were asked to perform endotracheal intubation of a Laerdal Airway Management Trainer with a $8 \mathrm{~mm}$ internal diameter endotracheal tube, using two different VLS, without any previous knowledge of their technical use, but before and after watching a video demonstration of the technique.

The VLS were the King Vision ${ }^{\circledR}$ (Ambu Srl) and the AP Advance $^{\mathrm{TM}}$ (APA, Venner Medical) both unchanneled. The primary endpoints were intubation time, number of attempts and overall success rate of tracheal intubation for each participant. Failed intubation was defined as trachea not intubated or time of process exceeded $120 \mathrm{~s}$.

Statistics: t-Student test and Chi-Square test when appropriate.

\begin{tabular}{|c|c|c|c|}
\hline & $\begin{array}{c}\text { Before } \\
\text { demonstration }\end{array}$ & $\begin{array}{c}\text { After } \\
\text { demonstration }\end{array}$ & $\mathrm{p}$ \\
\hline King Vision $\mathbb{}$ & $212 \pm 121 \mathrm{~s}$ & $121 \pm 91 \mathrm{~s}$ & 0,020 \\
\hline APA $^{\mathrm{TM}}$ & $102 \pm 80 \mathrm{~s}$ & $81 \pm 96 \mathrm{~s}$ & 0,119 \\
\hline
\end{tabular}

\section{Results and discussion:}

The time needed to perform endotracheal intubation, was significantly longer with King Vision ${ }^{\circledR}$ with respect to APA $^{\text {TM}}$ : $212 \pm 121$ vs $102 \pm 80 \mathrm{sec}(\mathrm{p}=0.027)$. We reported 3 failed intubation cases for King Vision ${ }^{\circledR}$ and in 1 for the APA $^{\mathrm{TM}}$. After watching the video demonstration, the average time was lower with both devices: $121 \pm 91 \mathrm{sec}$ vs $81 \pm 96 \mathrm{sec}$, but with a difference between the two VLS not statistically significant ( $\mathrm{p}=$ 0.309). Therefore, the difference in the intubation time recorded before and after videos resulted statistically significant for the King Vision ${ }^{\circledR}(p=0.020)$, but not significant using the $\operatorname{APA}^{\mathrm{TM}}(\mathrm{p}$ $=0.119$ ).

The training provides a significant advantage only in the case of King Vision ${ }^{\circledR}$. APA $^{\mathrm{TM}}$ is based on a Macintosh blade, users are familiar with the handling of this blade type, while King Vision ${ }^{\circledR}$ is designed with a highly angled blade that passes around the tongue and allows "a look around the corner" to the glottic opening requiring a different technique for endotracheal intubation $^{3}$. 